and a second person should supervise the tourniquet during the operation. The hazard warning provoked an unprecedented number of inquiries but nevertheless a further, similar death took place about two weeks later. ${ }^{\text {? }}$

Three elements merit discussion: the equipment, the drugs, and the people who used them. Firstly, reliable isolation of the circulation of the limb is essential to prevent a bolus of local anaesthetic reaching the circulation. A blood pressure cuff may be adequate so long as it is secured and the supervisor of the technique is prepared continually to monitor the pressure and adjust it. The bicycle pump type of tourniquet is more convenient and certain in its operation. These two systems share the great merit of simplicity and each has a single gauge which shows the cuff pressure. The multiplicity of switches on automatic equipment introduces hazards from misunderstanding and malfunction. A common error is to assume that a gauge shows the cuff pressure when it actually shows the pressure available inside the machine. The machines are expensive and have if anything increased the incidence of tourniquet failure during orthopaedic surgery (J Spencer, personal communication); they are at present the subject of an evaluation programme by the Scientific and Technical Branch. Complex equipment has many times proved to be no substitute for common sense and undivided attention; its failure should provoke articles, ${ }^{8}$ not disaster.

Reports on the safety of the technique have concentrated on signs of toxicity after release of the tourniquet; various minimum times (for example, 20 minutes) have been recommended to allow fixation of the drug in the tissues and thus reduce peak arterial concentrations after release. The likelihood of direct intravenous injection during routine use has been underestimated; the effects of the bolus are likely to be worse in a frightened patient as circulating catecholamines will ensure that the maximum amount of the cardiac output reaches the brain and heart, which are the main target organs for toxicity.

Secondly, the systemic toxicity of local anaesthetic drugs is in direct proportion to their potency. Given equivalent concentrations, volume, and rate of entry to the circulation, prilocaine has the theoretical advantage of greater extraction in the lungs; its ability to cause methaemoglobinaemia is irrelevant to intravenous regional analgesia. ${ }^{9}$ It has yet to become popular in Britain, though the case for its use has been well argued. ${ }^{6-11}$ Bupivacaine is normally less toxic than lignocaine ${ }^{12}{ }^{13}$ because of its greater fixation in tissues and more rapid metabolism. These factors are not relevant to the effects of a bolus and may have encouraged the use of unnecessarily high doses. Thus Rawlings and Staniforth ${ }^{4}$ reported good results from using only $10 \mathrm{ml}$ of $0.25 \%$ bupivacaine, allowing a few extra minutes for analgesia to develop.

The recognition and treatment of toxic reactions are crucial; even if accidents could be eliminated, there remain the possibilities of individual low thresholds ${ }^{14}$ or abnormal venous drainage within bones. Excellent descriptions of the necessary treatment have been given by $S \operatorname{cott}^{15}$ and Moore $e t$ al ${ }^{16}$ : speed, oxygen, and thiopentone are the most important features. A training film is urgently needed, with adequate simulation of a range of toxic reactions. In particular, neither sleepiness nor talkativeness are widely recognised as important symptoms of toxicity. Hypoxia occurs with terrifying rapidity in a patient having convulsions, and the fact that deaths occur show how inadequate are the standard resuscitation procedures in accident and emergency departments (though these are frequently successful in other circumstances).

Considerable time and skill are required to teach a succession of senior house officers to the necessary standard; an average district general hospital would have to train one each month in addition to training its anaesthetic staff. This time must offset the possible saving in the requirement for anaesthetic services. Anaesthetic departments should offer as comprehensive a service as possible; only anaesthetists are likely to have the confidence and skill to maintain oxygenation and give thiopentone quickly enough to prevent tragedy. If my son requires intravenous regional analgesia I would prefer to wait until an anaesthetist was available.

Consultant Anaesthetist,

Margaret L Heath

Lewisham Hospital,

London SE13 6LH

1 Ware RJ. Intravenous regional analgesia using bupivacaine. A double blind comparison with lignocaine. Anaesthesia 1979;34:231-5.

${ }^{2}$ Rousso M, Wexler MR, Weinberg H, Magora F. Regional anaesthesia for hand surgery. Prog Surg 1979;16:44-52.

3 Chan KM, Ma GFY, Chow YN, Leung PC. Intravenous regional anaesthesia in hand surgery-experience with 632 cases. Hand 1981 ; $13: 192-8$.

4 Rawlings ID, Staniforth P. Intravenous regional anaesthesia in upper limb trauma. Injury 1979;10:231-4.

5 Fitzgerald B. Intravenous regional anaesthesia in children. $\mathrm{Br} \mathcal{F}$ Anaesth $1976 ; 48: 485-6$.

6 Wildsmith JAW. Techniques of local anaesthesia. Update 1981;22:693-702.

7 Treatment of foot led to death, inquest is told. Enfield Gazette and Observer 1982 June 11:12 (cols 3-7).

8 Thorp JM, Railton R. Hypoxia due to air in the oxygen pipeline. A case for oxygen monitoring in theatre. Anaesthesia $1982 ; 37: 683-7$.

9 Wildsmith JAW, Scott DH, Brown DT. Intravenous regional analgesia using bupivacaine. Anaesthesia 1979;34:919-20.

10 Wildsmith JAW, Tucker GT, Cooper S, Scott DB, Covino BG. Plasma concentrations of local anaesthetics after interscalene brachial plexus block. Br $\mathcal{F}$ Anaesth 1977;49:461-6.

11 Wildsmith JAW, Scott DHT, Scott DB. Adverse reaction to bupivacaine. Br Med f 1980;281:1287.

${ }^{12}$ Gooding JM, Tavakoli MM, Fitzpatrick WO, Bagley JN. Bupivacaine: preferred agent for intravenous regional anesthesia. South Med F 1981; 74:1282-3.

13 Ware RJ, Caldwell J. Clinical and pharmacological studies of IV regional analgesia using bupivacaine. Br $\mathcal{F}$ Anaesth 1976;48:1124-5.

14 Albright GA. Cardiac arrest following regional anesthesia with etidocaine or bupivacaine. Anesthesiology 1979;51:285-7.

15 Scott DB. Toxicity caused by local anaesthetic drugs. Br F Anaesth 1981; $53: 553-4$.

${ }^{16}$ Moore DC, Thompson GE, Crawford RD. Long-acting local anesthetic drugs and convulsions with hypoxia and acidosis. Anesthesiology 1982; $56: 230-2$.

\section{Monetarism and health}

Last month the Government's "think tank" produced for the Cabinet a paper suggesting radical cuts in public spending including a proposal for replacing the NHS with a scheme based on private health insurance. ${ }^{1}$ Now, with astute political timing, the Nuffield Provincial Hospitals Trust has just published a collection of essays ${ }^{2}$ on private and public financing of health care in Britain, our European neighbours, and in North America.

The essayists recognise that at first sight the European systems would look attractive to politicians wanting to cut public spending and reduce the part played by central government in the planning and control of the health services. In reality, however, a close examination of other systems shows that they are desperately anxious to restrain the increasing proportion of their gross domestic products spent on health; and, whereas in Britain public expenditure on the NHS can be controlled and balanced against other programmes such as education (and defence, with all its contentious overtones), 
governments with insurance-based health schemes increasingly find themselves forced into subsidies and direct payments to the health system with no final control over its costs.

Typically in Western European countries citizens pay a percentage of wages before tax into an insurance scheme. Employers have to make a contribution too. Pensioners have to pay a reduced premium, while payments for the unemployed come from the public purse. In most countries the premiums cover the full costs of medical care, but in France and Belgium the insurance covers only $80 \%$ of the cost of primary care and minor hospital treatments. As medical costs have risen in the past decade the proportion of the average wage spent on these premiums has risen-in Germany, for example, from $8 \%$ in 1960 to $12 \%$ in 1982 - and governments have introduced more and more controls in attempts to limit the pace of expansion of hospitals and expensive technological innovations.

Furthermore, in all technically developed countries, no matter how the medical services are financed, governments have continued to support the poor, the elderly, and the chronic sick. In every society a substantial section of the community (including many heavy users of medical services) will be unable to buy health insurance in the open marketso that, like it or not, governments become embroiled in assessments of the costs, efficiency, distribution, and rationing of health care.

So much is common ground among those familiar with the problems (which may not include every self-styled expert prepared to theorise about health care and market economics). Equally clear is the massive upheaval that would be caused by any radical restructuring of the NHS, still suffering from the residual tremors of two reorganisations. Presumably the NHS would continue its responsibility for primary care (certainly neither doctors nor patients have shown any enthusiasm for private practice systems when they have been promoted as competitors with the NHS). What about the hospital sector, however? Would an insurance-based system encourage greater efficiency through competition-and would the savings be greater than the administrative costs of the insurance system?

The fallacy of the market ideology as applied to medical care is exposed very clearly in the final section of the Nuffield book: the theorists ignore the factors that blunt the competitive mechanisms. A competitive, free-market system could cut costs-but only provided professional licensure was abolished. Milton Friedman may well be right ${ }^{3}$ to argue that professional power has been used to raise doctors' incomes above market rates and to inhibit their substitution by nurses and other medical ancillaries. Health care could be provided more cheaply and doctors' incomes reduced by opening up a freely competitive system.

A second prerequisite would be the introduction of some price barrier to consumption so that the consumer/patient could be reimbursed by insurance for only part of his treatment. This would encourage patients to look for cheaper substitutes for doctors and dentists.

Surely such a dramatic transformation cannot be the intention of the think-tank's planners? What seems more likely is that they believe that public expenditure is unproductive and that by transferring health care to the "private" sector taxes would be cut and so incentives be provided for private initiative.

Two objections can be advanced to this thinking. Firstly, and by far the most important, it flies in the face of history. One hundred and fifty years ago over $70 \%$ of the work forcelaboured to feed themselves and the rest of the population. Now that proportion is below $5 \%$-even in countries self-sufficient in food. Within the last 50 years the proportion of the work force in the manufacturing industry has fallen from $40 \%$ to $20 \%$ and the trend is still sharply downwards. ${ }^{4}$ Before the end of the century with increasing automation agriculture, mining, power generation, and manufacturing will occupy no more than onefifth of the population available for work. Government planners should be taking account of these realities and looking for ways of expanding the service industries and government enterprises if we are to see any end to massive unemployment. The concluding essay in the Nuffield Book is plain spoken on this issue: "Adherents to the liberal market ideology are concerned with the advancement of wealth creation and the decline of the economy manifested as the contraction of its (private) manufacturing base and the expansion of the public (service) sector. As Simon Kusnets has noted this is a natural way for growing economies to develop. Analysts with this particular view of the world believe that public sector activity is wasteful at worst or less valuable than its private counterpart. In the case of the health services some of its assumptions look less than secure. The view is curious as it seems to imply that a necessary hernia procedure done in an NHS hospital is less valuable than a similar hernia procedure completed in a private hospital."

The example of the hernia brings us to the second objection to a switch to an insurance-based system. Evidence from countries with such systems indicates that more operations are done per head of population at greater cost. Britain spends less on health than any of its neighbours. Goodness knows, the NHS needs more money-but for investment in clinical facilities, not the cost of restructuring and administering a new system of finance. Perhaps health insurance would raise the proportion of gross domestic product spent on health, but only if that rise was substantial enough for a genuine expansion of the service would the benefits be visible to society as a whole. True, in any insurance-based scheme British doctors' incomes would almost certainly rise closer to the average in Europebut at what price? Once the work force is covered by insurance the danger is that the non-earning underprivileged sections of society may face a continuing decline in their provision-as has happened in the United States.

Possibly other means will need to be found to channel more of the national wealth into the medical services, making them a growth industry, and to increase their efficiency. Health maintenance organisations (in which a community pays a group of doctors and other health professionals a fixed annual fee for all medical services) have distinct advantages in terms of cost-cutting incentives. Some aspects of the NHS, such as the laundry and catering services, might be made more efficient by privatisation. ${ }^{5}$ Surely, however, the experience of our European neighbours is enough to show that an insurance-based system for Britain would simply replace one set of problems with another? The Nuffield essayists conclude-and we share this opinion-that reorganisations of the NHS and rhetoric about the optimum mix of public and private sectors have diverted attention from the fundamental problem of finding ways to control or moderate costs and services and make the optimum use of resources. They do not claim to know all the answers; but at least they are asking the right questions.

${ }^{1}$ Anonymous. Britain. Economist 198218 September:25. Col 3.

${ }^{2}$ McLachlan G, Maynard A, eds. The public/private mix for health. The relevance and effects of change. London: Nuffield Provincial Hospitals Trust, 1982.

${ }^{3}$ Friedman M. Capitalism and Freedom. Chicago: University of Chicago Press, 1962.

${ }^{4}$ Ginzberg E. The mechanization of work. Sci Am 1982;247:39-47.

${ }^{5}$ Anonymous. Enough is enough. Br Med $\mathcal{F} 1982 ; 285: 669-70$. 